\title{
Health behaviors and health services accessibility factors associated with diabetes: a propensity score matching analysis
}

Songul Cinaroglu ( $\sim$ songulcinaroglu@gmail.com )

Hacettepe University

Research

Keywords: Diabetes, health behaviors, accessibility of health services, nursing care developing countries, Turkey

Posted Date: July 20th, 2020

DOl: https://doi.org/10.21203/rs.3.rs-42654/v1

License: (c) (1) This work is licensed under a Creative Commons Attribution 4.0 International License. Read Full License

Version of Record: A version of this preprint was published at Expert Review of Endocrinology \& Metabolism on December 1st, 2020. See the published version at https://doi.org/10.1080/17446651.2021.1853526. 


\section{Abstract}

Introduction: This study aims to explore diabetes prevalence and to identify the associated health behaviors and accessibility factors. Despite increasing burden of diabetes in Turkey, there is a lack of information regarding associated factors with diabetes.

Methods: Data gathered from TurkStat-Health Survey for the year 2014. 1996 individuals who had reported diabetes were matched to similar non-diabetes participants in terms of socio-demographic characteristics and comorbidities by using 1:1 nearest matching based on estimated propensity scores.

Results: The weighted point prevalence of diabetes among adults was $8.98 \%$. Compared with smokers, non-smokers were less likely to develop diabetes (OR:0.96; 95\% Cl:0.95-0.97). Individuals engaging in regular physical activity were less likely to have experienced diabetes than individuals not engaging in any physical activity (OR:0.51; $95 \% \mathrm{Cl}: 0.41-0.52)$. Conclusions: Improving the health behaviors of individuals and promoting a culture of exercise and healthy food consumption are necessary strategies to fight against diabetes in Turkey. Collaborations between health professionals will provide many lights for effective clinical decision making and preparations of diabetes self-management programs. Crisper understanding of associated health behaviors and health services accessibility factors associated with diabetes is beneficial to develop better nursing plans for patients.

\section{Introduction}

The increasing burden of diabetes is a problem for both developing and developed countries [1]. Turkey is one of the developing countries and has been facing the problem of increasing diabetes prevalence over the past decade [2,3]. The first cross-sectional population-based study conducted by Satman et al. (2002) [2] reported a prevalence of $7.2 \%$ in Turkey. The follow-up study on diabetes prevalence after 12 years showed that the prevalence has increased to 13.7\% [3]. Recent studies emphasize that diabetes is one of the major challenges of the health care system in the near future $[4,5]$. Furthermore, it has been suggested that among the European countries, the prevalence of diabetes will be higher in Turkey by the year 2035 [6].

Diabetes is one of the chronic diseases generally influenced by complex physical, social, and environmental factors [7]. Perceived and actual diabetes knowledge among health professionals and nurses about diabetes is necessary for protocol development and patient care [8]. Because poorly informed and empowered individuals with diabetes are less likely to have better self-care behaviours [9]. Moreover, enhancement of self-management skills of individuals about chronic diseases is important for better management of scarce financial resources in developing countries. Better management of scarce health resources is critical Turkey is one of the countries undergoing enormous economic and social changes. Acemoglu and Ucer (2015) [10] examined the quality of Turkish economic growth and emphasized that between the years 2002 and 2006 Turkey had experienced a high-quality economic growth. However, since 2007, the growth observed in Turkey has been of lower quality. There is a growing concern that rapid economic growth results in important social changes [11]. Recent literature reports that changes in standard of living and health behaviors of Turkish people parallel with economic growth. High consumption level is one of the most distinguishing features of Turkish consumers [12]. Moreover, the fast food industry has also grown rapidly in Turkey [13]. On the other hand, Turkey is also experiencing health reforms since the past decade, and it has been suggested that accessibility of health care services has increased with reform policies, and the number of people diagnosed with diabetes has also increased [4]. Altogether, due to the changing pattern of consumption, unhealthy eating behavior, and the reformist environment in health care, it is essential to examine the trend and current situation of diabetes in Turkey. This study aims to provide an updated picture of diabetes prevalence among adults in Turkey while examining the trend of this disease. To this end, this study examines the prevalence of diabetes, classify adults with diabetes and non-diabetes by creating balanced groups and using risk factors such as sociodemographic factors and comorbidities. After that, logistic regression analysis was performed to identify associated health behaviors and accessibility of health services factors with diabetes. The next sections of this article are organized as follows: the following section includes information about data and analysis methods. The third section describes the study results and final sections are discuss the study results and makes strategic recommendations about how to tackle the increasing diabetes prevalence by emphasizing the pioneering role of nursing care.

\section{Methods}

\section{Study population}

Data were obtained from the Turkish Statistical Institute-Health Survey (TurkStat-THS) conducted for the year 2014 [14]. TurkStat-THS was conducted by TurkStat every 2 years since 2008 to determine the health profile of the population. The total sample size determined 
was 9.740 households for the year 2014 to represent total, rural, and urban parts of the country. As a result of the survey, a total of 19.129 individuals aged $\geq 15$ years were interviewed during the year 2014 . The health survey was designed to collect general information about sociodemographic characteristics and general health status of the population. Thus, the primary objective of this survey did not include determination of the prevalence and risk factors of diabetes. The study findings were weighted later to obtain values that would represent the total population. Data collected from 1.996 adults during the year 2014, who reported having diabetes, formed the basis of the present study. In this study data obtained from official and regal sources of TurkStat and this study did not include Institutional Review Board approval.

\section{Measures}

\section{Sociodemographic characteristics, comorbid conditions, health behaviors and accessibility of health care services}

In this study, sociodemographic characteristics and comorbid factors were determined as adjustment variables of PSM diabetes. Adults who reported that they have "diabetes" during the 12 months prior to the interview was the outcome of this study. Individuals' age, gender, marital status, occupational status, and health insurance were determined as the sociodemographic characteristics. Heart disease, hypertension, stroke, arthritis, asthma, depression and sleeping disorders were determined as comorbid factors of diabetes. Information regarding health care services utilization and accessibility of health care services during the previous 12 months were collected from individuals, irrespective of whether they had experienced smoking, physical activity and healthy eating behavior. Additionally, whether their blood sugar, blood cholesterol and blood pressure was checked by a health professional during the previous 12 months (e.g. answered as "yes", if had blood sugar check, "no" if not).

\section{Statistical analysis}

The TurkStat-THS provided the weighted data for individual participants of each survey to represent the whole population. Descriptive characteristics of participants were presented as unweighted numbers and weighted percentages. Frequencies and weighted percentages were computed for categorical variables. All analyses incorporated sampling weights. Self-reported diabetes was determined as the outcome. Individuals' age, gender, marital status, health insurance, occupational status, and comorbid factors of diabetes were used as covariates in the analyses. Chi-square tests $\left(X^{2}\right)$ were used to evaluate the statistical significance of differences between diabetes and non-diabetes groups before matching, in terms of baseline characteristics of individuals. To reduce differences among baseline variables between groups, propensity score matching (PSM) was used. The exposure for the propensity model was the presence of diabetes. Propensity score model included variables which may contribute to the presence and diagnosis of diabetes (age, gender, marital status, occupational status, health insurance and comorbidities). Individuals were matched on the basis of the propensity scores by using nearest-neighbor method. The matching ratio is 1:1. To evaluate the balance of covariates before and after matching, standardized difference was estimated [15]. A value of standardized difference $\nabla 10 \%$ is acceptable, as a level $\nabla 10 \%$ may indicate imbalance between variables [16]. Factors associated with diabetes were examined using logistic regression analysis. The logistic regression model is one of the multivariate analysis methods and most widely used when the prediction of a disease or health status is of interest. This is a good classifier when the relationship between the input and output variables is linear and the data are balanced between groups [17]. All statistical analyses were performed with the use of $\mathrm{R}$ version 3.0.2. A two-tailed P-value of $₫ 0.05$ was considered statistically significant.

\section{Results}

\section{Diabetes prevalence and descriptive characteristics of adults with and without diabetes before and after matching}

Diabetes prevalence and descriptive statistics for sociodemographic characteristics and comorbid factors of diabetes and non-diabetes individuals are presented in Table 1. In this study, a total of 1.996 subjects reported having diabetes and 17.133 subjects reported not having diabetes, in the year 2014. Thus, the weighted diabetes prevalence in the community for the year 2014 was $8.98 \%$.

Table 1 Baseline characteristics of patients in the diabetes and non-diabetes groups before and after propensity score matching 


\begin{tabular}{|c|c|c|c|c|c|c|c|c|c|c|c|}
\hline \multirow{3}{*}{$\begin{array}{l}\text { Socio-demographic } \\
\text { characteristics / } \\
\text { comorbidities }\end{array}$} & \multicolumn{5}{|c|}{ Before matching } & \multicolumn{2}{|c|}{ Matching } & \multicolumn{2}{|c|}{ After } & \multicolumn{2}{|c|}{$\begin{array}{l}\text { Standardized } \\
\text { Mean } \\
\text { Difference }\end{array}$} \\
\hline & \multicolumn{2}{|c|}{$\begin{array}{l}\text { Diabetes } \\
(\mathrm{N}=1996)\end{array}$} & \multicolumn{2}{|c|}{$\begin{array}{l}\text { Non- } \\
\text { Diabetes } \\
(\mathrm{N}=17133)\end{array}$} & \multirow[t]{2}{*}{$\begin{array}{l}\mathrm{P} * * \\
\text { Value }\end{array}$} & \multicolumn{2}{|c|}{$\begin{array}{l}\text { Diabetes } \\
(\mathrm{N}=1996)\end{array}$} & \multicolumn{2}{|c|}{$\begin{array}{l}\text { Non- } \\
\text { Diabetes } \\
(\mathrm{N}=1996)\end{array}$} & \multirow[t]{2}{*}{ Before } & \multirow[t]{2}{*}{ After } \\
\hline & $\mathbf{N}$ & $\begin{array}{l}\mathrm{Wt} \\
(\%) *\end{array}$ & $\mathbf{N}$ & $\begin{array}{l}\text { Wt } \\
(\%) *\end{array}$ & & $\mathbf{N}$ & $\begin{array}{l}\mathrm{Wt} \\
(\%) *\end{array}$ & $\mathbf{N}$ & $\begin{array}{l}\mathrm{Wt} \\
(\%)^{*}\end{array}$ & & \\
\hline \multicolumn{12}{|l|}{ Age } \\
\hline$<75$ & 1788 & $\begin{array}{l}89.87 \\
\%\end{array}$ & 16414 & $\begin{array}{l}96.55 \\
\%\end{array}$ & $<0.001$ & 1788 & $89.87 \%$ & 1782 & $89.96 \%$ & 0.203 & -0.009 \\
\hline$\geq 75$ & 208 & $\begin{array}{l}10.12 \\
\%\end{array}$ & 719 & $\begin{array}{l}3.44 \\
\%\end{array}$ & $<0.001$ & 208 & $10.12 \%$ & 214 & $10.03 \%$ & -0.228 & 0.001 \\
\hline \multicolumn{12}{|l|}{ Gender } \\
\hline Male & 714 & $\begin{array}{l}36.97 \\
\%\end{array}$ & 8007 & $\begin{array}{l}49.25 \\
\%\end{array}$ & $<0.001$ & 714 & $36.96 \%$ & 713 & $37.88 \%$ & 0.084 & 0.013 \\
\hline Female & 1282 & $\begin{array}{l}63.03 \\
\%\end{array}$ & 9126 & $\begin{array}{l}50.74 \\
\%\end{array}$ & $<0.001$ & 1282 & $63.03 \%$ & 1283 & $62.11 \%$ & -0.214 & 0.039 \\
\hline \multicolumn{12}{|l|}{ Marital Status } \\
\hline Married & 1535 & $\begin{array}{l}75.83 \\
\%\end{array}$ & 11626 & $\begin{array}{l}64.15 \\
\%\end{array}$ & $<0.001$ & 1535 & $75.83 \%$ & 1568 & $77.03 \%$ & 0.370 & 0.010 \\
\hline $\begin{array}{l}\text { Not Married } \\
\text { (Single\&Widowed\&Divorced) }\end{array}$ & 461 & $\begin{array}{l}24.16 \\
\%\end{array}$ & 5507 & $\begin{array}{l}35.84 \\
\%\end{array}$ & $<0.001$ & 461 & $24.16 \%$ & 428 & $22.96 \%$ & -0.213 & 0.002 \\
\hline \multicolumn{12}{|l|}{ Occupational status } \\
\hline Currently employed & 1039 & $\begin{array}{l}50.84 \\
\%\end{array}$ & 9643 & $\begin{array}{l}55.48 \\
\%\end{array}$ & $<0.001$ & 1039 & $50.84 \%$ & 1052 & $52.67 \%$ & 0.860 & -0.003 \\
\hline Currently not-employed & 957 & $\begin{array}{l}49.15 \\
\%\end{array}$ & 7490 & $\begin{array}{l}44.51 \\
\%\end{array}$ & $<0.001$ & 957 & $49.15 \%$ & 944 & $47.32 \%$ & 0.126 & 0.058 \\
\hline \multicolumn{12}{|l|}{ Health Insurance } \\
\hline General Insured & 1925 & $\begin{array}{l}95.57 \\
\%\end{array}$ & 15845 & $\begin{array}{l}91.16 \\
\%\end{array}$ & $<0.001$ & 1925 & $95.57 \%$ & 1926 & $95.63 \%$ & 0.309 & 0.025 \\
\hline Uninsured & 71 & $\begin{array}{l}4.42 \\
\%\end{array}$ & 1288 & $\begin{array}{l}8.83 \\
\%\end{array}$ & $<0.001$ & 71 & $4.42 \%$ & 70 & $4.36 \%$ & 0.341 & 0.003 \\
\hline \multicolumn{12}{|l|}{ Comorbidities } \\
\hline Heart Disease & 459 & $\begin{array}{l}23.52 \\
\%\end{array}$ & 1270 & $\begin{array}{l}7.13 \\
\%\end{array}$ & $<0.001$ & 459 & $23.52 \%$ & 450 & $23.95 \%$ & 0.216 & 0.024 \\
\hline Hypertension & 1131 & $\begin{array}{l}56.67 \\
\%\end{array}$ & 2404 & $\begin{array}{l}12.2 \\
\%\end{array}$ & $<0.001$ & 1131 & $56.67 \%$ & 1134 & $54.31 \%$ & 0.388 & 0.011 \\
\hline Stroke & 54 & $\begin{array}{l}3.27 \\
\%\end{array}$ & 111 & $\begin{array}{l}0.66 \\
\%\end{array}$ & $<0.001$ & 54 & $3.27 \%$ & 35 & $1.86 \%$ & 0.126 & 0.058 \\
\hline Arthritis & 438 & $\begin{array}{l}21.46 \\
\%\end{array}$ & 1335 & $\begin{array}{l}6.91 \\
\%\end{array}$ & $<0.001$ & 438 & $21.46 \%$ & 435 & $21.37 \%$ & 0.341 & 0.003 \\
\hline Asthma & 389 & $\begin{array}{l}19.50 \\
\%\end{array}$ & 1239 & $\begin{array}{l}6.82 \\
\%\end{array}$ & $<0.001$ & 389 & $19.50 \%$ & 369 & $18.60 \%$ & 0.309 & 0.025 \\
\hline Depression & 387 & $\begin{array}{l}19.62 \\
\%\end{array}$ & 1855 & $\begin{array}{l}10.69 \\
\%\end{array}$ & $<0.001$ & 387 & $19.62 \%$ & 368 & $19.02 \%$ & 0.216 & 0.024 \\
\hline $\begin{array}{l}\text { Insomnia/Sleeping } \\
\text { Disorders }\end{array}$ & 1072 & $\begin{array}{l}53.08 \\
\%\end{array}$ & 5885 & $\begin{array}{l}34.10 \\
\%\end{array}$ & $<0.001$ & 1072 & $53.08 \%$ & 1061 & $54.79 \%$ & 0.388 & 0.011 \\
\hline
\end{tabular}


Comparison of the descriptive statistics of the subjects who reported not having diabetes and those who reported having diabetes in the year 2014 showed the follows aspects: age $\geq 75$ years (10.12\% vs. $3.44 \%)$, female gender $(63.03 \%$ vs. $50.74 \%)$, married $(75.83 \%$ vs. $64.15 \%)$, currently unemployed ( $49.15 \%$ vs. $44.51 \%)$, and insured $(95.57 \%$ vs. $91.16 \%)$. All these differences were marginally significant $(P<0.001$; Table 1$)$. Comorbidity rates for heart disease ( $23.52 \%$ vs. $7.13 \%)$, hypertension $(56.67 \%$ vs. $12.20 \%)$, stroke $(3.27 \%$ vs. $0.66 \%)$, arthritis $(21.46 \%$ vs. $6.91 \%)$, asthma (19.50\% vs. $6.82 \%)$, depression ( $19.62 \%$ vs. $10.69 \%)$, and insomnia/sleeping disorders ( $53.08 \%$ vs. $34.10 \%)$ showed marginally significant differences $(P<0.001$ for all).

Comparison of the descriptive statistics of the two groups after matching showed the following results: age $\geq 75$ years $(10.12 \%$ vs. $10.03 \%)$, female gender (63.03\% vs. $62.11 \%)$, married ( $75.83 \%$ vs. $77.03 \%)$, currently unemployed $(49.15 \%$ vs. $47.32 \%)$, and insured $(95.57 \%$ vs. $95.63 \%)$. All these differences were marginally significant $(P<0.001 ;$ Table 1$)$. Comorbidity rates for heart disease $(23.52 \%$ vs. $23.95 \%$ ), hypertension ( $56.67 \%$ vs. $54.31 \%)$, stroke (3.27\% vs. $1.86 \%$ ), arthritis $(21.46 \%$ vs. $21.37 \%)$, asthma (19.50\%vs. $18.60 \%)$, depression (19.62\% vs. $19.02 \%)$ and insomnia/sleeping disorders $(53.08 \%$ vs. $54.79 \%)$ were higher among adults with diabetes. It is seen

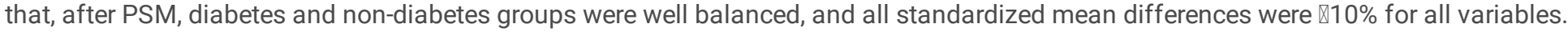

\section{Balanced diagnostics and propensity scores}

Figure 1 shows absolute standardized mean differences in baseline characteristics of diabetes individuals compared to non-diabetes participants before and after 1:1 PSM. In this figure " $y$ " axis show baseline characteristics. " $x$ " axis was the percentage of absolute difference "before" and "after" matching. It is seen that, prior to matching there exists large differences in the mean values of hypertension between diabetes and non-diabetes individuals. The figure shows that PSM reduced standardized differences for most observed baseline characteristics below $10 \%$ in absolute values, except employment status and stroke. Distribution of propensity scores shows that there are not unmatched treatment units.

\section{Factors associated with diabetes}

The odds ratios (OR) and $95 \%$ confidence intervals (Cls) from the logistic regression analyses of health behaviors and accessibility of health care services changes with respect to the likelihood of developing diabetes are presented in Table 2. Compared with smokers, nonsmokers were less likely to develop diabetes (OR: $0.96 ; 95 \% \mathrm{Cl}: 0.95-0.97)$. Additionally, individuals engaged in regular physical activity were less likely to have experienced diabetes than individuals didn't engage in any physical activity (OR: $0.51 ; 95 \%$ Cl: $0.41-0.52)$. Furthermore, reporting of diabetes was more among individuals eating healthy (OR: 1.10; 95\% Cl: 1.09-1.11).

Table 2. A comparison of health behaviors and accessibility of health services of individuals with diabetes and propensity score matched non-diabetes 


\begin{tabular}{|c|c|c|c|c|c|c|}
\hline \multirow{3}{*}{$\begin{array}{l}\text { Health Behaviors / Accessibility of Health Care } \\
\text { Services }\end{array}$} & \multirow{3}{*}{$\begin{array}{l}\text { Diabetes } \\
\mathrm{N} \\
(\%)^{*}\end{array}$} & \multirow{3}{*}{$\begin{array}{l}\text { Non- Diabetes } \\
\text { N } \\
(\%)^{*}\end{array}$} & \multirow[t]{3}{*}{$O R^{\star *}$} & \multicolumn{2}{|c|}{$95 \%$ Cl*** } & \multirow{3}{*}{$\begin{array}{l}P \\
\text { value }\end{array}$} \\
\hline & & & & \multirow[b]{2}{*}{ Lower } & \multirow[b]{2}{*}{ Upper } & \\
\hline & & & & & & \\
\hline Study N & 1996 & 1996 & & & & \\
\hline \multicolumn{7}{|l|}{ Health Behaviors } \\
\hline \multicolumn{7}{|l|}{ Smoking } \\
\hline No & $518 \quad(24.9 \%)$ & $\begin{array}{c}450 \\
(22.3 \%)\end{array}$ & 0.96 & 0.95 & 0.97 & $<0.001$ \\
\hline Yes (Reference) & $1478(75.1 \%)$ & $\begin{array}{l}1546 \\
(77.7 \%)\end{array}$ & & & & \\
\hline \multicolumn{7}{|l|}{ Physical Activity } \\
\hline \multirow[t]{2}{*}{ Yes } & 48 & $(3.7 \%)$ & 0.51 & 0.41 & 0.52 & $<0.001$ \\
\hline & $(2.1 \%)$ & & & & & \\
\hline No (Reference) & $1948(97.9 \%)$ & 1907 (96.3\%) & & & & \\
\hline \multicolumn{7}{|l|}{ Healthy Eating Behavior } \\
\hline Yes & $367 \quad(17.1 \%)$ & $\begin{array}{c}314 \\
(15.4 \%)\end{array}$ & 1.10 & 1.09 & 1.11 & $<0.001$ \\
\hline No (Reference) & $\begin{array}{c}1629 \\
(82.9 \%)\end{array}$ & $1682(85.2 \%)$ & & & & \\
\hline \multicolumn{7}{|l|}{ Accessibility of Health Care Services } \\
\hline \multicolumn{7}{|l|}{ Blood Sugar Check } \\
\hline No & $333(17.9 \%)$ & $\begin{array}{c}981 \\
(51.1 \%)\end{array}$ & 0.15 & 0.14 & 0.16 & $<0.001$ \\
\hline Yes (Reference) & $1663(82.1 \%)$ & $1015(48.9 \%)$ & & & & \\
\hline \multicolumn{7}{|l|}{ Blood Cholesterol Check } \\
\hline No & $487(25.3 \%)$ & $\begin{array}{c}993 \\
(51.6 \%)\end{array}$ & 1.07 & 1.06 & 1.08 & $<0.001$ \\
\hline Yes (Reference) & 1509 (74.7\%) & $1003(48.4 \%)$ & & & & \\
\hline \multicolumn{7}{|l|}{ Blood Pressure Check } \\
\hline No & $375(18.9 \%)$ & $\begin{array}{c}596 \\
(31.1 \%)\end{array}$ & 1.59 & 1.58 & 1.60 & $<0.001$ \\
\hline Yes (Reference) & 1621 (81.1\%) & $1400 \quad(68.9 \%)$ & & & & \\
\hline
\end{tabular}

Notes: *Weighted percentages ${ }^{*}$ OR: Odds Ratio, ${ }^{\star \star \star} \mathrm{Cl}$ : $95 \%$ Confidence Interval. Logistic regression models incorporated sampling weights.

On the other hand, compared with individuals whose blood sugar was checked by health professionals, among those blood sugar was not checked were less likely to have diabetes (OR: $0.15 ; 95 \% \mathrm{Cl}$ : 0.14-0.16). Reporting of diabetes was more among individuals whose blood cholesterol was not checked by health professionals than among those blood cholesterol was checked with an odds ratio of 1.07 . Finally, reporting of diabetes was more among individuals whose blood pressure was not checked by health professionals than among those whose blood pressure was monitored by health professionals with an odds ratio of 1.59 (Table 2).

Discussion

Diabetes is a growing health problem in developing countries. Minority groups and economically disadvantageous groups are more affected by diabetes [18]. Although an increasing global prevalence of diabetes is observed, the rate of increase shows a wide variation 
[19]. Turkey is one of the middle-income countries, and recent population-based studies have reported an increasing prevalence of diabetes in recent years [3]. The results of the present study show that point prevalence of diabetes in the community was $8.98 \%$ for the year 2014. Furthermore, smoking, physical activity, blood pressure and cholesterol check are associated factors with diabetes.

The results of this study highlight high prevalence of diabetes in Turkey. Good policies to overcome the risk factors of diabetes are essential to fight against this increasing burden. However, not much is known about the associated health behavior and health services utilization factors of diabetes. Results of this study are generally consistent with published literature that shows that factors such as smoking [20] physical activity [21], health eating behavior [22], blood pressure check and blood cholesterol check [23] are strongly associated with diabetes reporting. Despite diabetes is an emerging health problem in Turkey, to the best of our existing knowledge, there is a lack of evidence about the associated health behavior and health services accessibility factors with diabetes. Ensuring nurses' awareness about the associated health behavior and health services accessibility factors with diabetes is essential for evidence-based nursing practices in diabetes care.

From another point of view, Turkey is experiencing major economic and health reforms since the past decade [24]. This economic growth causes structural changes in the social life of individuals. However, the quality of growth of Turkish economy has not always been the same. The economic growth after 2007 was driven by consumption and supported by the government, with negative productivity growth observed during that time, which is defined as economic growth of low quality [10]. Economy policies encouraging increased consumption are still continuing till 2016 [25]. Studies regarding the consumption patterns of Turkish people have shown that food consumption constitutes the biggest part of households' consumption in Turkey [26], and high consumerism is one of the major characteristics of Turkish people in recent years. Moreover, increase in smoking [27] unhealthy dietary habits such as eating fast foods and eating outside $[12,28]$ and increase in health services utilization [29] are distinguishing features of high consumer groups in Turkey $[12,28]$. Therefore, Turkey has experienced a consumption based economic growth that fosters an unsustainable and stressful consumption environment that will ultimately lead to an increasing diabetes crisis in Turkey in the near future. Thus, it has been reported that depression and stress factors are highly comorbid factors of diabetes and changes in dietary habits will help to reduce depressive symptoms among adults, especially for those with diabetes [30]. Encouragement, education and providing high-level thinking for nurses about associated socio-economic and accessibility factors with diabetes may help to foster knowledge transfer about good self-care from nurses to patients.

Based on the results of this study indicating high prevalence of diabetes in Turkey, it is necessary that health care policy makers in Turkey implement urgent policy actions to fight against diabetes. Policy actions to overcome the risk factors such as smoking, peer education of people with diabetes, encouraging self-management of diabetes, and promoting a culture of exercise and dietary tactics using social media campaigns are the primary strategies to fight against diabetes. Moreover, recent studies about diabetes among children indicate that the prevalence is increasing among children as well [31]. Improving the awareness of children about diabetes from an early age, improving self-management skills, and summer camps to educate children about monitoring their blood sugar levels and eating healthy are strategies that can help build a healthy future [32]. Finally, effective nursing care planning and improved diabetes care supervision are essential to overcome diabetes across the country.

\section{Limitations}

This study has some limitations. First, our analysis was based on TurkStat-THS data. The primary objective of TurkStat-THS did not include determination of the prevalence of diabetes in the population. The primary objective of that survey was to collect information about the general health status of the population. Second, the data were collected for management purposes. The differences in diabetes prevalence between previously published population-based studies and our study results could be attributed to the primary purpose of data collection.

\section{Implications for clinical practice}

Results of this study indicate that drawing more attention to the increasing prevalence of diabetes should be supported as a strategic goal to fight against diabetes in Turkey. Moreover, this study highlights the need for collaborative nursing care to improve the health behaviors of individuals to fight against high diabetes prevalence. Nurses play a pioneering role and leading effort to improve public awareness about increasing diabetes prevalence and to fight against associated risk factors. It is highly advisable for nurses to better understand associated health behaviors and health services accessibility factors with diabetes before they help patients about selfmanagement of diabetes. Promoting a culture of exercise and improving number of diabetes diagnosis is critical to enhance patients

Page $7 / 10$ 
self-awareness and management of diabetes. This study draws the attention of health professionals in Turkey for the need for better planning of nursing services to combat with diabetes.

\section{Conclusions}

To conclude, there was a high prevalence of diabetes among adults for the year 2014. Continues monitoring of diabetes prevalence and further studies are recommended to determine the causes of high prevalence of diabetes while suggesting effective strategies to overcome the associated factors of diabetes. It is anticipated that future studies would examine the diabetes trend in detail in different population groups such as children, youth, and elderly population. We hope that the results of this study form a basis for future policy actions to improve partnership with the health care community and the government to explore the associated factors of diabetes. Ensuring collaborative diabetes care by incorporating nurses into diabetes care teams and continuous monitoring of self-management of diabetes are essentials to better fight against noncommunicable diseases.

\section{Declarations}

\section{Ethics approval and consent to participate}

Not applicable

\section{Consent for publication}

Not applicable

\section{Availability of data and material}

Please contact author for data requests.

\section{Competing interest}

There is no competing interest related with this study.

\section{Funding}

Not applicable

\section{Authors' contribution}

Songul Cinaroglu design, analyze, read, approved and submitted the final manuscript.

\section{Acknowledgement}

Not applicable

\section{References}

1. Wild S, Roglic G, Green A, Sicree R, King H. Global prevalence of diabetes. Diabetes Care. 2004;27(5):1047-53. https://doi.org/10.2337/diacare.27.5.1047.

2. Satman I, Yılmaz T, Sengul A, et al. Population-based study of diabetes and risk characteristics in Turkey. Diabetes Care. 2002;25(9):1551-56. https://pubmed.ncbi.nlm.nih.gov/12196426/. 
3. Satman I, Beyhan O, Tutuncu Y, et al. Twelve-year trends in the prevalence and risk factors of diabetes and prediabetes in Turkish adults. Eur J Epidemiol. 2013;28(2):169-80.

https://www.ncbi.nlm.nih.gov/pmc/articles/PMC3604592/pdf/10654_2013_Article_9771.pdf.

4. Tatar M. Management of diabetes and diabetes policies in Turkey. Globalization Health. 2013;9(16):1-7. https://www.ncbi.nlm.nih.gov/pmc/articles/PMC3644279/pdf/1744-8603-9-16.pdf.

5. Burki T. Country in focus: Diabetes prevalence on the rise in Turkey. Lancet Diabetes Endocrinol. 2016;4(5):391-2. doi:10.1016/S2213-8587(16)00090-5.

6. Guariguata L, Whiting DR, Hambleton I, et al. Global estimates of diabetes prevalence for 2013 and projections for 2035 . Diabetes Res Clin. 2014;103(2):137-49. https://doi.org/10.1016/j.diabres.2013.11.002.

7. Hill J, Nielsen M, Fox MH. Understanding the social factors that contribute to diabetes: A means to informing health care and social policies for the chronically III. The Permanente Journal. 2013;17(2):67-72.

https://www.ncbi.nlm.nih.gov/pmc/articles/PMC3662286/.

8. Alotaibi A, Gholizadeh L, Al-Ganmi A, et al. Examining perceived and actual diabetes knowledge among nurses working in a tertiary hospital. Appl Nurs Res. 2017;35:24-9. doi:10.1016/j.apnr.2017.02.014.

9. D'Souza MS, Karkada SN, Parahoo K, et al. Self-efficacy and self-care behaviours among adults with type 2 diabetes. Appl Nurs Res. 2017;36:25-32. doi:10.1016/j.apnr.2017.05.004.

10. Acemoglu S, Ucer M. The Ups and Downs of Turkish Growth, 2002-2015: Political Dynamics, the European Union and the Institutional Slide. The National Bureau of Economic Research, http://www.nber.org/papers/w21608. 2015. Accessed on: 01.10. 2019.

11. Toffler A. Revolutionary wealth. NPQ. 2006;23(3):7-15. https://doi.org/10.1111/j.1540-5842.2006.00818.x.

12. Uner MM, Gungordu A. The new middle class in Turkey: a qualitative study in a dynamic economy. Int Bus Rev. 2016;25:668-78. https://doi.org/10.1016/j.ibusrev.2015.11.002.

13. Akbay C, Tiryaki GY, Gul A. Consumer characteristics influencing fast food consumption in Turkey. Food Control. 2007;18(8):904 13. https://doi.org/10.1016/j.foodcont.2006.05.007.

14. Turkish Statistical Institute-Turkey Health Survey (TurkStat-THS) http://www.turkstat.gov.tr/PreHaberBultenleri.do?id=18854 Accessed on: 16.9.2019.

15. Austin PC. Balance diagnostics or comparing the distribution of basline covariates between treatment groups in propensity-score matched samples. Stat Med. 2009;28(25):3083-107. https://www.ncbi.nlm.nih.gov/pmc/articles/PMC3472075/.

16. Yang X, Sun F, Chen L, et al. Prognostic value of visceral pleural invasion in non-small cell lung cancer: A propensity score matching study based on the SEER registry. J Surg Oncol. 2017;116(3):398-406.

17. Bagley SC, White H, Golomb BA. Logistic regression in the medical literature: Standards for use and reporting, with particular attention to one medical domain. J Clin Epidemiol. 2001;54(10):979-85. doi:10.1016/s0895-4356(01)00372-9.

18. King H, Rewers M. Global estimates for prevalence of diabetes mellitus and impaired glucose tolerance in adults. WHO Ad Hoc Diabetes Reporting Group. Diabetes Care. 1993;16(1):157-77. https://pubmed.ncbi.nlm.nih.gov/8123057/.

19. Dwyer-Lindgren L, Machenback JP, van Lenthe FJ, et al. Diagnosed and undiagnosed diabetes prevalence by country in the US, 1999-2012. Diabetes Care. 2016;39(9):1556-62. https://doi.org/10.2337/dc16-0678.

20. Alshaarawya O, Elbazb HA. Serum cotinine levels and diabetes mellitus in never smokers. J Diabetes Complicat. 2015;29(8):1032-6. doi:10.1016/j.jdiacomp.2015.08.018.

21. Colberg SR, Sigal RJ, Yardley JE, et al. Physical activity/exercise and diabetes: a position statement of the American Diabetes Association. Diabetes Care. 2016;39(11):2065-79. https://doi.org/10.2337/dc16-1728.

22. Goff LM, Moore AP, Rivas C, et al. Healthy Eating and Active Lifestyles for Diabetes (HEAL-D): study protocol for the design and feasibility trial, with process evaluation, of a culturally tailored diabetes self-management programme for African-Caribbean communities. BMJ Open. 2019;9:e023733. http://dx.doi.org/10.1136/bmjopen-2018-023733.

23. Khunti K, Kosiborod M, Ray KK. Legacy benefits of blood glucose, blood pressure and lipid control in individuals with diabetes and cardiovascular disease: time to overcome multifactorial therapeutic inertia? Diabetes Obes Metab. 2018;20(6):1337-41. doi:10.1111/dom.13243.

24. Akdag R. Turkey health transformation program assessment report (2003-2011). [in Turkish]. 2012. T.C. Ministry of Health. https://sbu.saglik.gov.tr/Ekutuphane/Yayin/452 Accessed on: 27.11.2019. 
25. Organization for Economic Co-operation and Development (OECD). Turkey - Economic forecast summary (June 2016). 2016. http://www.oecd.org/economy/turkey-economic-forecast-summary.htm Accessed on: 02.10.2019.

26. Akbay C, Boz I, Chern WS. Household food consumption in Turkey. Eur Rev Agric. 2007;34(2):209-31. https://doi.org/10.1093/erae/jbm011.

27. Mucan B, Moodie C. Young adult smokers' perceptions of plain packs, numbered packs and pack inserts in Turkey: a focus group study. Tob Control. 2018;27:631-6. http://dx.doi.org/10.1136/tobaccocontrol-2017-053902.

28. Chambers D, Phan UT, Chanadang S, et al. Motivations for food consumption during specific eating occasions in Turkey. Foods. 2016;5(2):1-14. https://www.ncbi.nlm.nih.gov/pmc/articles/PMC5302344/pdf/foods-05-00039.pdf.

29. Hone T, Gurol-Urgancı I, Millett C, et al. Effect of primary health care reforms in Turkey on health service utilization and user satisfaction. Health Policy Plan. 2017;32(1):57-67. https://pubmed.ncbi.nlm.nih.gov/27515404/.

30. Dipnall JF, Pasco JA, Meyer D, et al. The association between dietary patterns, diabetes and depression. J Affect Disord. 2015;174:215-24. https://doi.org/10.1016/j.jad.2014.11.030.

31. Yesilkaya E, Cinaz P, Andiran N, et al. First report on the nationwide incidence and prevalence of Type 1 diabetes among children in Turkey. Diabetes Medicine. 2016;34(3):405-10. https://pubmed.ncbi.nlm.nih.gov/26814362/.

32. Copeland KC, Silverstein J, Moore KR, et al. Management of newly diagnosed type 2 diabetes mellitus (T2DM) in children and adolescents. Pediatrics. 2013;131(2):364-82. https://doi.org/10.1542/peds.2012-3494.

\section{Figures}

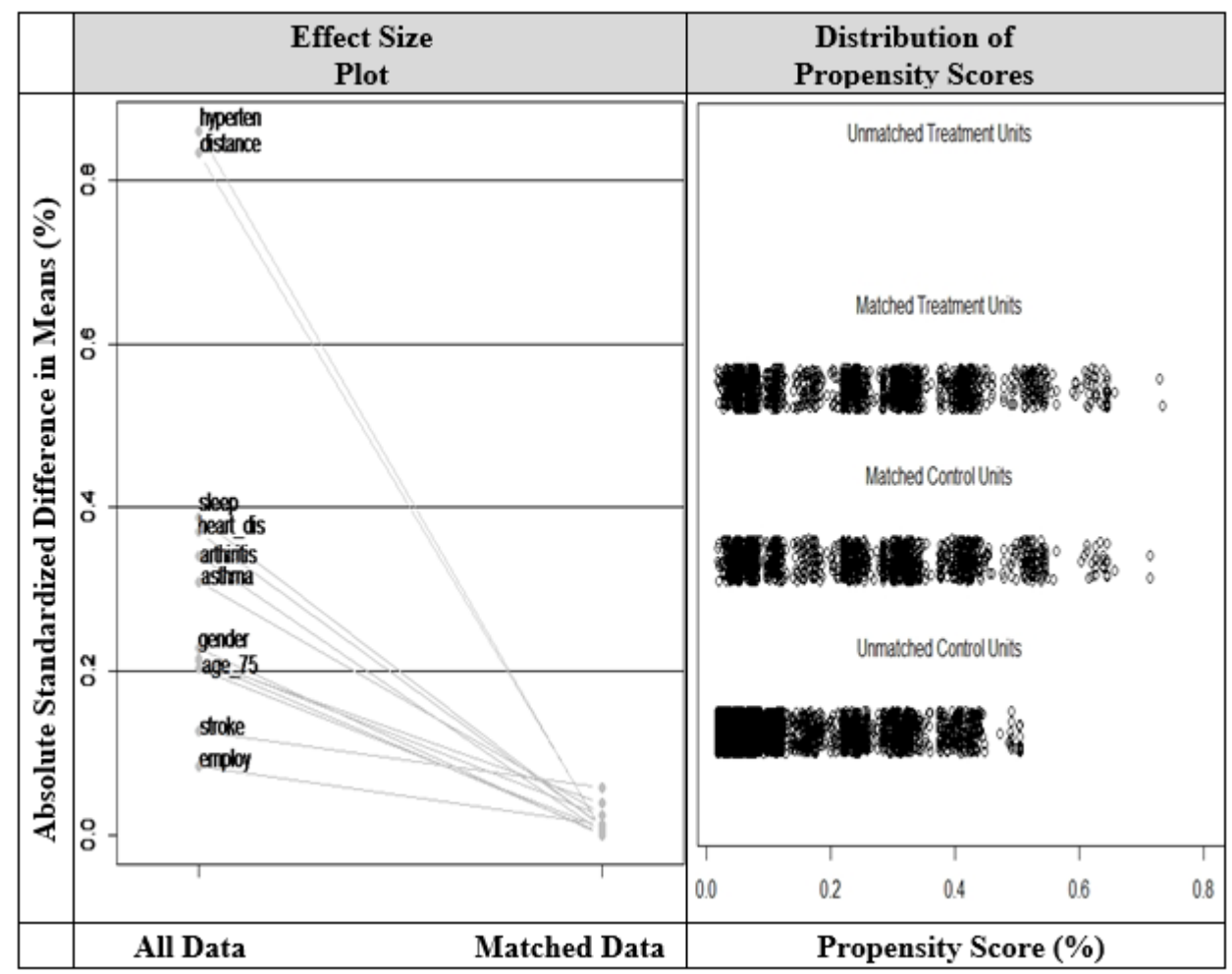

Figure 1

Balanced diagnostics and distribution of propensity scores 